\title{
Originals
}

\section{The Genetic Susceptibility to Type 1 (Insulin-Dependent) Diabetes: Analysis of the HLA-DR Association}

\author{
E. Wolf, K. M. Spencer and A. G. Cudworth \\ Department of Diabetes and Immunogenetics, Medical Unit, St Bartholomew's Hospital, London, UK
}

\begin{abstract}
Summary. HLA-DR and MT1, MT2, MT3 genotypes have been investigated in 123 Type 1 (insulin-dependent) diabetic subjects and their families. Ninety-eight percent of probands possessed either DR3 (relative risk $=5.0$ ), or DR4 (relative risk $=6.8$ ) or both antigens (relative risk $=14.3$ ), emphasizing the strong association of the disease with these two antigens. Almost $51 \%$ of the probands were DR3, DR4 heterozygotes. The DR antigen combinations of the parents leading to DR3, DR4 heterozygous and to DR3 and DR4 homozygous offspring were analysed. There was a marked increase in DR3, DR4 heterozygosity, but no increase in homozygosity for these antigens compared with the expected frequencies. These results are compatible with the existence of two susceptibility genes operating at a locus or at loci closely linked to that of HLA-DR. There was a striking reduction of DR7 (rela-
\end{abstract}

tive risk $=0.1$ ) and only five probands possessed DR2 (relative risk $=0.1$ ). In each case, the other inherited allele was DR3 or DR4. Linkage disequilibrium between B7 and DR2 was much lower in the haplotypes of the probands than in the 'non-diabetic' parental haplotype. In contrast, the association of BW62 with DR4 was more pronounced in the haplotypes of the probands. There was no increase in recombination frequency in these families and no strong effect of HLA-DR on age of onset could be demonstrated. There was a significant shift towards DR identity compared with identity for the whole HLA haplotype (A, B, C and DR) in both healthy and diabetic siblings $(p<0.025)$.

Key words: Type 1 diabetes, HLA-DR genotypes, genetic susceptibility.
It is now widely accepted that the genetic basis of Type 1 (insulin-dependent) diabetes is quite different from that of Type 2 (non-insulin-dependent) diabetes. The different patterns of familial aggregation and the studies in identical twins illustrate this genetic heterogeneity at the clinical level, but the scientific evidence to confirm the difference in genetic susceptibility of these two major forms of diabetes only became available after 1973, when certain antigens of the HLA-B locus (B15, $\mathrm{B} 8, \mathrm{~B} 18, \mathrm{~B} 40$ ) were shown to have a positive association with Type 1, but not with Type 2 diabetes [1-3]. Some of these studies also showed a significant negative association with B7. Evidence for an HLA linked susceptibility gene or genes was provided by studies of multiplex families $[4,5]$.

A stronger association with DW3 and DW4 was found in 1975 [6] and reports of an association with certain D-related (DR) antigens soon followed. These findings were confirmed at the Seventh and Eighth International Histocompatibility Workshops [7, 8]. However, important arguments still exist concerning (a) whether there is one or more than one susceptibility gene $[9,10]$, (b) the mode of inheritance $[11,12]$, (c) the mechanism of action of such genes, and (d) whether or not the presence of DR3 or DR4 indicates heterogeneity in pathogenesis [8].

In 1978, a long-term investigation, the 'Barts-Windsor prospective family study', was started whose aim was to compare the immunogenetic characteristics of the siblings of Type 1 diabetic subjects who may be potentially susceptible or non-susceptible to the development of diabetes. We have performed genotyping for HLA-DR and for MT1, MT2 and MT3 in a large number of these families [13-15]. Most previous studies of the HLA-DR system have either analysed DR phenotypes only or, in those studies in which DR genotypes were considered, not all the recognised DR antigens were defined $[16,17]$. None included data on MT1, MT2, MT3 which might be either 'supertypic' specificities which could be considered as public antigens, or specificities coded at a different locus to HLA-DR, although closely linked to it [18]. 


\section{Subjects and Methods}

\section{Diabetic Families}

One-hundred and twenty-three Caucasoid families living in the Windsor area in East Berkshire, UK, were investigated. These families were selected because of the presence of one Type 1 diabetic child (the proband) and at least one non-diabetic sibling under the age of 20 years. Two hundred and twenty-eight parents and 326 children out of a total of 371 children ( $88 \%$ ) were genotyped for HLA-A, B, C and DR. Only 20 healthy siblings ( $5 \%$ ) were not available for HLA-A, B, C and DR typing and 25 healthy siblings (7\%) were typed for HLA-A, B, $\mathrm{C}$ but not for DR. Two of these were expaternal children. Nine families had two and one family had three diabetic children. Sixty-seven of the diabetic children were male (mean age of onset 9 years) and 56 were female (mean age of onset 9 years). In ten families one of the parents had Type 1 diabetes.

Unequivocal HLA-A, B, C and DR genotypes were obtained in 116 families. In five families, only one haplotype could be detected in one of the parents, and so homozygosity was assumed, particularly as four cases possessed the commonly found A1, CW7, B8, DR3 haplotype. In two families, DR genotypes could not be established as both parents possessed the same DR antigen combinations.

In 18 families, only one parent was typed for DR and therefore one or both parental DR antigens were deduced from the results found in the children. In four families, an expaternal child was found by HLA-A, B, C typing. Only two of these were DR typed. One of them was a diabetic proband and this family (two parents and one healthy sibling) was excluded from most analyses. In five families there were two pairs of monozygotic and four pairs of dizygotic twins. One of the monozygotic and three of the dizygotic twins had Type 1 diabetes.

\section{Control Subjects}

Volunteers from St Bartholomew's Hospital were used as healthy random control subjects. All were Caucasoids. Careful family histories were taken to exclude diabetes and other autoimmune diseases.

\section{HLA-A, B, C and -DR Typing}

Blood $(10 \mathrm{ml})$ was collected in $1 \mathrm{ml}$ citrate $(3.8 \%)$ and later defibrinated after adding one to two drops of thrombin $(50 \mathrm{IU} / \mathrm{ml})$ and $0.3 \mathrm{ml}$ of calcium gluconate $(10 \%)$. A modified National Institutes of Health microlymphocytotoxicity test was used for A, B, C typing [19] and a two-colour fluorescence technique was used for DR typing [20]. All tests were carried out either on cells obtained from fresh blood (up to $24 \mathrm{~h}$ ) or on previously separated cells kept in tissue culture medium 199 (Wellcome) at room temperature overnight. All A, B, C specificities recognised by the World Health Organization Nomenclature Committee and other new subgroups (TH, 8W59 etc.) were tested for, using a minimum of 120 well characterised antisera. All ten officially recognised DR specificities and MT1, MT2, MT3 were defined, using a minimum of 60 antisera, including many sera used at the Seventh and Eighth International Histocompatibility Workshops.

\section{Statistical Methods}

In the genotyped families gene frequencies were established by gene counting, whereas in the unrelated phenotyped control subjects, the gene frequencies were calculated using the formula $g=1-\sqrt{1-\mathrm{f}}$, where $g=$ gene frequency and $f=$ phenotype frequency. Relative risks were calculated using the Woolf method as modified by Haldane [21]. The probabilities estimated for comparing patients and control subjects were $2 \times p$, $p$ being derived from the normal probability integral of the corresponding $\chi^{2}$ values, this giving values nearly identical with those obtained with Fisher's exact test. These $2 p$ values were then corrected according to the numbers of specificities tested. The degree of association was also calculated with the $\delta$ formula of Bengtsson and Thomson [22] as $\delta=(\mathrm{FAD}-\mathrm{FAP}) /(1-\mathrm{FAP})$, where FAD denotes the frequency of the antigen in individuals with the disease and FAP the frequency of the antigen in the healthy population. This is termed the 'population attributable risk' or 'aetiologic fraction' and is a direct measure of the strength of the association between a disease susceptibility gene and the alleles of the HLA complex.

\section{Results}

The gene frequencies for all the recognised DR antigens and for MT1, MT2 and MT3 as established by gene counting in the 122 Type 1 diabetic probands are shown in Table 1. Compared with the unrelated healthy subjects, the increase in DR3 $\left(2 p 1.0 \times 10^{-5}\right.$, relative risk = $5.0)$ and DR4 $\left(2 p 1.0 \times 10^{-5}\right.$, relative risk $\left.=6.8\right)$ in Type 1 diabetic patients was confirmed. Only five subjects possessed DR2 $\left(2 p 1.0 \times 10^{-5}\right.$, relative risk $\left.=0.1\right)$ and there was also a significant reduction in the frequency of DR5 and DR7 $\left(2 p 0.7 \times 10^{-5}\right.$, relative risk = $0.06 ; 2 p 1.0 \times 10^{-5}$, relative risk $=0.1$ respectively). Table 1 also shows the $\delta$-values for the different DR antigens and their combinations [22]. Positive high values were found for DR3 and DR4 and negative values for DR2, DR5, the lowest negative value being found for DR7. The ranking order for the DR antigens, using $\delta$ values, is different from that obtained using relative risks, as $\delta$-values are not dependent on antigen frequency. Calculations of relative risks have the disadvantage of being derived from phenotype and not gene frequencies. This is also true for $\delta$-values although the latter may determine which of the relevant antigens have the strongest association with the disease.

The possible DR combinations are also shown in Table 1 . Nearly $98 \%$ of probands were positive for either DR3 or DR4 and 51\% of probands possessed both these antigens $\left(2 p 1.0 \times 10^{-5}\right.$, relative risk $\left.=14.3\right)$. In order to study DR3, DR4 heterozygosity further, we have analysed the different parental DR antigen combinations which could lead to DR3, DR4 heterozygous offspring. There were 71 families in whom possible DR3, DR4 offspring could occur. Four families with a single DR3, DR4 heterozygous proband had to be excluded from this analysis as one of the parents was not typed and only one DR allele could be deduced from the children (Table 2). In the 22 families where one parent possessed one DR3 antigen and the other parent one DR4 antigen, 30 out of 64 children $(47 \%)$ were DR3, DR4 heterozygous compared with the expected frequency of $25 \%$. Of these DR3, DR4 heterozygotes, 26 $(87 \%)$ had Type 1 diabetes. A similar trend towards increased observed DR3, DR4 heterozygosity was also seen in most of the other parental DR antigen combinations.

The same approach was used to determine the frequency of DR3 and DR4 homozygotes (Table 3). Thus, in 23 families in which there was the possibility of DR3 homozygous offspring and in 26 families in which there 
Table 1. HLA-DR gene and phenotype frequencies in Type 1 diabetic probands and healthy subjects

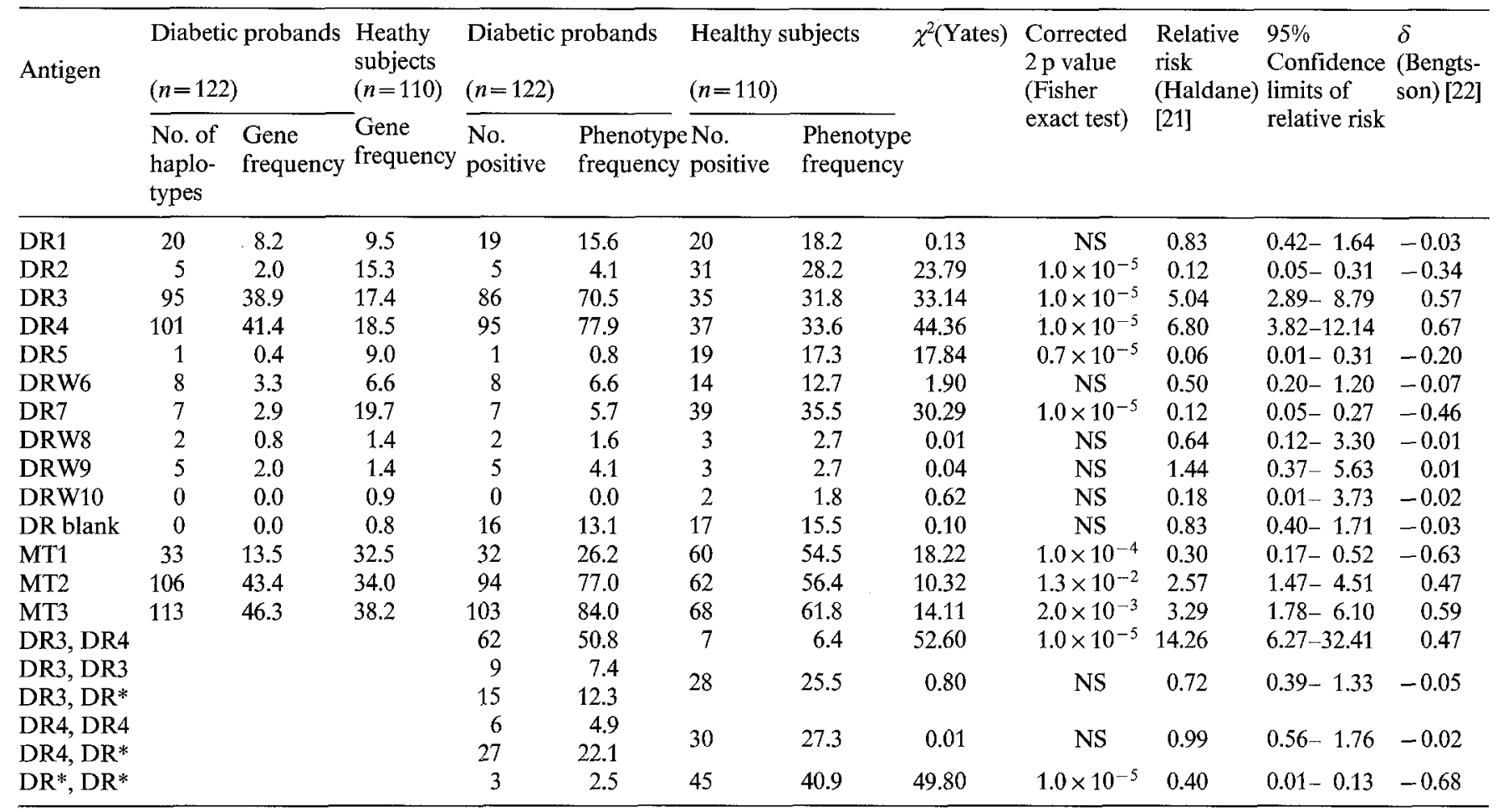

DR* symbolizes one of the following DR antigens: DR1, DR2, DR5, DRW6, DR7, DRW8, DRW9, DRW10 or DR blank. NS = not significant

was the possibility of DR4 homozygous offspring, the observed frequency of homozygous children was in the expected range. Thirty percent were DR3 homozygous and $20 \%$ were DR4 homozygous compared with the expected $25 \%$, when the parents had two DR antigens in common. When the parents had three DR antigens in common, $60 \%$ were DR3 homozygous and $50 \%$ were DR4 homozygous, compared with the expected $50 \%$. The distribution of DR3 and DR4 homozygosity was approximately equal in affected and unaffected children. Overall, there were ten DR3 homozygous (nine probands and one diabetic sibling) and six DR4 homozygous probands.

HLA haplotype identity (A, B, C and DR) with the proband for 178 healthy siblings and 11 Type 1 diabetic siblings is shown in Table 4. Thirteen healthy children belonging to seven families were excluded from this analysis because one child was expaternal. In nine others HLA identity or haplo-identity could not be established unequivocally because one of their parents was homozygous for HLA-A, B, C and DR and three children had to be excluded because one parent was not tested. Fifty of the healthy siblings and two of the diabetic siblings were HLA non-identical with the proband. If identity for DR is considered on its own, there is a significant shift towards DR identity and haploidentity in both the healthy and the diabetic siblings $(p<0.025)$ compared with identity for the whole haplotype. Of particular interest were the two HLA nonidentical diabetic siblings, one of whom became DR identical and one haplo-identical as a result of recombination.

Altogether we found four A-C recombinations (two in diabetic children and two in healthy siblings) and four B-DR recombinations, three occurring in Type 1 diabetics (two probands and one diabetic sibling). All the B-DR recombinations and one of the four A-C recombinations were of maternal origin. The frequency of A-C recombination in 502 informative meioses was $0.8 \%$ and of $\mathrm{B}-\mathrm{DR}$ recombination in 420 informative meioses was $0.9 \%$. Two expaternal children were excluded, together with the children of the two families in whom the parents possessed the same DR combinations, all children of five families in whom one parent was homozygous for A, B, C and DR and all children of families in whom one or both parents were homozygous for HLA-A or DR locus antigens respectively. This way all hidden $\mathrm{A}-\mathrm{C}$ and $\mathrm{B}-\mathrm{DR}$ recombinants were excluded. No $\mathrm{B}-\mathrm{C}$ recombination was found and no cross-over was observed between the DR-locus and the MT system [13-15].

Table 5 shows how often the different DR antigens occurred together in the same haplotype with the Blocus antigens relevant to Type 1 diabetes. Whereas $70 \%$ of the DR3 positive haplotypes were B8 positive in both the diabetic $\left(\Delta \times 1000=159, \chi^{2}=55.5\right)$ and 'nondiabetic' $\left(\Delta \times 1000=91, \chi^{2}=73.8\right)$ haplotypes, $39 \%$ of the DR4 positive haplotypes were BW62 in the diabetic haplotypes $\left(\Delta \times 1000=81, \chi^{2}=19.9\right)$ and only $9 \%$ in the 'non-diabetic' haplotypes $\left(\Delta \times 1000=9, \chi^{2}=1.1\right)$. 
Table 2. DR3, DR4 heterozygosity in 67 families

\begin{tabular}{|c|c|c|c|c|c|c|c|}
\hline \multirow{2}{*}{$\begin{array}{l}\text { Parental DR combinations } \\
\text { DR3, DR* versus DR4, DR* }\end{array}$} & \multirow{2}{*}{$\begin{array}{l}\text { No. of families } \\
22\end{array}$} & \multirow{2}{*}{$\begin{array}{l}\text { No. of children } \\
64\end{array}$} & \multicolumn{4}{|c|}{ No. of DR3, DR4 heterozygous children } & $\begin{array}{l}\text { Expected frequency } \\
\text { of DR3, DR4 } \\
\text { heterozygous } \\
\text { children (\%) }\end{array}$ \\
\hline & & & 30 & 47 & 26 & 4 & \multirow[b]{2}{*}{25} \\
\hline $\begin{array}{l}\text { DR3, DR4 versus DR3, DR* } \\
\text { DR3, DR4 versus DR4, DR* }\end{array}$ & $\begin{array}{r}12 \\
6\end{array}$ & $\begin{array}{l}40 \\
16\end{array}$ & 18 & 32 & 13 & 5 & \\
\hline DR3, DR4 versus DR3, DR4 & 3 & 6 & 5 & 83 & 2 & 3 & \multirow[t]{2}{*}{50} \\
\hline $\begin{array}{l}\text { DR3, DR4 versus DR3, DR3 } \\
\text { DR3, DR4 versus DR4, DR4 }\end{array}$ & $\begin{array}{l}2 \\
4\end{array}$ & $\begin{array}{r}7 \\
13\end{array}$ & 10 & 50 & 4 & 6 & \\
\hline DR3, DR3 versus DR4, DR4 & 1 & 2 & 1 & 100 & 1 & 1 & 100 \\
\hline
\end{tabular}

Overall there were 68 DR3, DR4 heterozygous diabetic children (62 probands and six diabetic siblings) DR* = DR1, DR2, DR5, DRW6, DR7, DRW8, DRW9 or DRW10

Twenty percent of the DR2 positive diabetic haplotypes were B7 positive $\left(\Delta \times 1000=3, \chi^{2}=0.1\right)$ in contrast with $53 \%$ of the 'non-diabetic' haplotypes $(\Delta \times 1000=68$, $\chi^{2}=29.9$ ).

In our study there were $16 \mathrm{~B} 7$ positive probands, but only one of these was DR2 positive. His mother was A2, CW7, B7, DR2 homozygous. One B7 positive proband was a B-DR recombinant and inherited DR1 instead of DR2. Nine of the B7 positive probands were DR4 positive (Table 5). There were, however, another four DR2 positive Type 1 diabetic patients without B7. All five DR2 positive subjects possessed either DR3 or DR4 as the alternative DR allele.

Not a single CW6, BW57, DR7 haplotype was found in the diabetic probands, whereas there were seven 'non-diabetic' parental haplotypes containing these specificities. The most commonly found haplotype in these Type 1 diabetic families was the A1, CW7, $\mathrm{B} 8, \mathrm{DR} 3$. In 43 families with a single, informative A1, CW7, B8, DR3 haplotype, there were 113 children of whom $60 \%$ inherited this particular haplotype compared with the alternative parental haplotype $\left(\chi^{2}=\right.$ $4.47, p<0.05$ ).

We were unable to demonstrate any association between DR and age of onset. In the three age groups analysed (0-5, 6-10 and 11-25 years), the frequency of DR3, DR4 heterozygosity was $47 \%, 56 \%$ and $49 \%$, respectively, and the overall frequency of DR4 was $74 \%$, $79 \%$ and $80 \%$ respectively. The mean age of onset for DR4 positive probands was 9.1 years and the mean age of onset for DR3 positive probands was 8.9 years and for probands who possessed both DR3 and DR4 the mean age of onset was 9.2 years. It was claimed at the Eighth Histocompatibility Workshop [8] that DR4 was significantly more frequent if the onset of the disease is in the last 3 months of the year. We have compared the frequencies of the different DR antigen combinations (DR3, DR4; DR3, DR*; DR4, DR*) in this period with the frequencies of these combinations in the other months of the year, including the spring peak. No differences were found.

\section{Discussion}

The results from the present study emphasize the strong association of Type 1 diabetes with the two DR antigens, DR3 and DR4. In fact, $98 \%$ of the Type 1 diabetic probands studied possessed either DR3 or DR4 or both. This raises the possibility that these antigens themselves might be directly involved in the initial pathogenesis of pancreatic B cell destruction. Although it is very likely that DR antigens are not expressed on healthy islet cells, it is possible that they may be expressed after damage (e. g. by viruses).

An alternative explanation for their high frequency could be the existence of immune response genes in linkage disequilibrium with DR3 and DR4 respectively which control the underlying susceptibility to diabetes. An important question concerns whether one or two different genes are operating. We have attempted to examine this problem by high-lighting the importance of DR3, DR4 heterozygosity in markedly increasing the susceptibility to diabetes, compared with the risk of possessing DR3 or DR4 alone. We believe that these results are best interpreted by postulating the existence of two separate susceptibility genes operating in an interactive way. A powerful argument in favour of this is the lack of increase of DR3 and DR4 homozygotes in the diabetic subjects.

No attempt has previously been made to analyse the different parental DR antigen combinations which could lead to DR3, DR4 heterozygous or DR3 or DR4 homozygous offspring. Out of the 186 children belonging to 67 families, $93(50 \%)$ were DR3, DR4 heterozygous. This represents a marked excess compared with the expected frequency, particularly when one considers that in 26 families ( 64 children) the chances for a 
Table 3. DR3 and DR4 homozygosity in 49 families

\begin{tabular}{|c|c|c|c|c|c|c|c|c|c|c|c|}
\hline Antigen & $\begin{array}{l}\text { No. of DR3- or DR4- } \\
\text { positive haplotypes in } \\
\text { both parents }\end{array}$ & $\begin{array}{l}\text { No. of } \\
\text { families }\end{array}$ & $\begin{array}{l}\text { No. of } \\
\text { children }\end{array}$ & \multicolumn{4}{|c|}{ No. of homozygous children ${ }^{a}$} & \multicolumn{4}{|c|}{ No. of heterozygous children ${ }^{b}$} \\
\hline DR3 & 3 & 4 & 10 & 6 & 60 & 2 & 4 & 4 & 40 & 2 & 2 \\
\hline & 4 & 1 & 2 & 2 & 100 & 1 & 1 & 0 & & & \\
\hline & 2 & 20 & 46 & 9 & 20 & 4 & 5 & 37 & 80 & 15 & 22 \\
\hline & 4 & 1 & 3 & 3 & 100 & 1 & 2 & 0 & & & \\
\hline
\end{tabular}

a Overall there were ten DR3 homozygous (nine probands and one diabetic sibling) and six DR4 homozygous diabetic children (all probands). Expected frequency of DR3 or DR4 homozygous children is $25 \%$ when there are two, $50 \%$ when there are three and $100 \%$ when there are four haplotypes with either DR3 or DR4 in both parents. ${ }^{b}$ Heterozygous children are either DR3, DR*; DR4, DR*; DR3, DR4 or DR*, DR* (DR* = DR1, DR2, DR5, DRW6, DR7, DRW8, DRW9 or DRW10)

Table 4. HLA haplotype (A, B, C and DR) and DR identity in relation to the probands

\begin{tabular}{|c|c|c|c|c|c|c|}
\hline & \multicolumn{3}{|c|}{$\begin{array}{l}\text { Healthy siblings } \\
(n=178)\end{array}$} & \multicolumn{3}{|c|}{ Diabetic siblings $(n=11)$} \\
\hline & $\begin{array}{l}\text { Iden- } \\
\text { tical }\end{array}$ & $\begin{array}{l}\text { Haplo- } \\
\text { iden- } \\
\text { tical }\end{array}$ & $\begin{array}{l}\text { Non- } \\
\text { iden- } \\
\text { tical }\end{array}$ & $\begin{array}{l}\text { Iden- } \\
\text { tical }\end{array}$ & $\begin{array}{l}\text { Haplo- } \\
\text { iden- } \\
\text { tical }\end{array}$ & $\begin{array}{l}\text { Non- } \\
\text { iden- } \\
\text { tical }\end{array}$ \\
\hline \multicolumn{7}{|c|}{ HLA haplotype } \\
\hline $\begin{array}{l}(\mathrm{A}, \mathrm{B}, \mathrm{C} \\
\text { and } \mathrm{DR})\end{array}$ & 33 & 95 & 50 & 5 & 4 & $2^{\mathrm{a}}$ \\
\hline DR alone & 49 & 102 & 27 & 6 & 5 & 0 \\
\hline
\end{tabular}

${ }^{a}$ One A-C recombination led to DR identity and one B-DR recombination led to DR haplo-identity

DR3, DR4 heterozygous child was $50 \%$ and in one family (two children) even 100\%. The majority $(69 \%)$ of these DR3, DR4 heterozygous children had Type 1 diabetes. Although these families were a priori selected for the presence of a diabetic child the excess of DR3, DR4 heterozygosity over the other possible DR combinations was higher than expected. In contrast, the number of observed DR3 and DR4 homozygous children was in the 'expected' range.

There was a significant tendency for DR identity to be more pronounced than HLA-A, B, C and DR haplotype identity in both healthy and diabetic siblings. There was only a small number of affected siblings $(n=$ 11) and all of these were DR-identical or haplo-identical with the proband. Two of them were HLA-A, B, C non-identical with the proband but, due to recombination, they became DR-identical and DR haplo-identical respectively. These findings are consistent with the hypothesis that identity for the D, DR end of the chromosome is more important than identity for the whole happlotype in determining susceptibility to diabetes.

The frequencies of $\mathrm{A}-\mathrm{C}$ and $\mathrm{B}-\mathrm{DR}$ recombination were $0.7 \%$ and $0.9 \%$ respectively. The recombination rate was similar in affected and non-affected children. No recombination was found between the DR-locus and the MT system. One B-DR recombinant was not informative and in the two other B-DR recombinants the appropriate MT specificity travelled with the DR end of the chromosome. It has been reported that one of these recombinants was a cross-over between the established DR-locus and a postulated new DR-locus [23]. We could not confirm this using the MT system.

The strength of linkage disequilibrium seen in the haplotypes of diabetic probands was different from that observed in the 'non-diabetic' parental haplotypes, especially with regard to BW62-DR4, B7-DR2 and BW57-DR7. Whereas B8-DR3 showed the same amount of association in both types of haplotypes, $39 \%$ of all DR4 haplotypes of the probands were BW62 positive compared with $9 \%$ in the 'non-diabetic' haplotypes. Only one proband was $\mathrm{B} 7$ and DR2 positive so that only $6 \%$ of all B7 positive haplotypes were associated with DR2 compared with $60 \%$ of all B7 positive "non-diabetic' haplotypes. That is, $20 \%$ of DR2 haplotypes of probands were $\mathrm{B} 7$ positive, in contrast to $53 \%$ of the "nondiabetic' B7 haplotypes.

No CW6, BW57, DR7 haplotype was found in the diabetic probands. In contrast, there were seven 'nondiabetic' parental haplotypes containing these specificities. Twenty-four percent of all DR7 positive 'non-diabetic' parental haplotypes were BW57 positive and 70\% of all BW57 positive 'non-diabetic' parental haplotypes were associated with DR7. These results indicate for the first time the importance of the low frequency of DR7 in Type 1 diabetes. That the strength of linkage disequilibrium found in haplotypes of diabetic probands is different from that found in 'non-diabetic' parental haplotypes may have important implications. Variable strength of linkage disequilibrium may also exist in other diseases which have HLA associations.

Only five Type 1 diabetic children possessed DR2, and in each case the alternative allele inherited from the other parent was either DR3 or DR4. Similarly, of the eleven DR7 positive Type 1 diabetic probands, six possessed DR4 and three DR3 as the alternative allele.

B7 was mainly associated with DR4 in the diabetic haplotypes in contrast with the 'non-diabetic' parental haplotypes where the strong linkage disequilibrium between B7 and DR2 was maintained. This again raises 
Table 5. HLA-DR in relation to certain HLA-B antigens based on 232 haplotypes of 116 diabetic probands (P) and 'non-diabetic' parental haplotypes (ND)

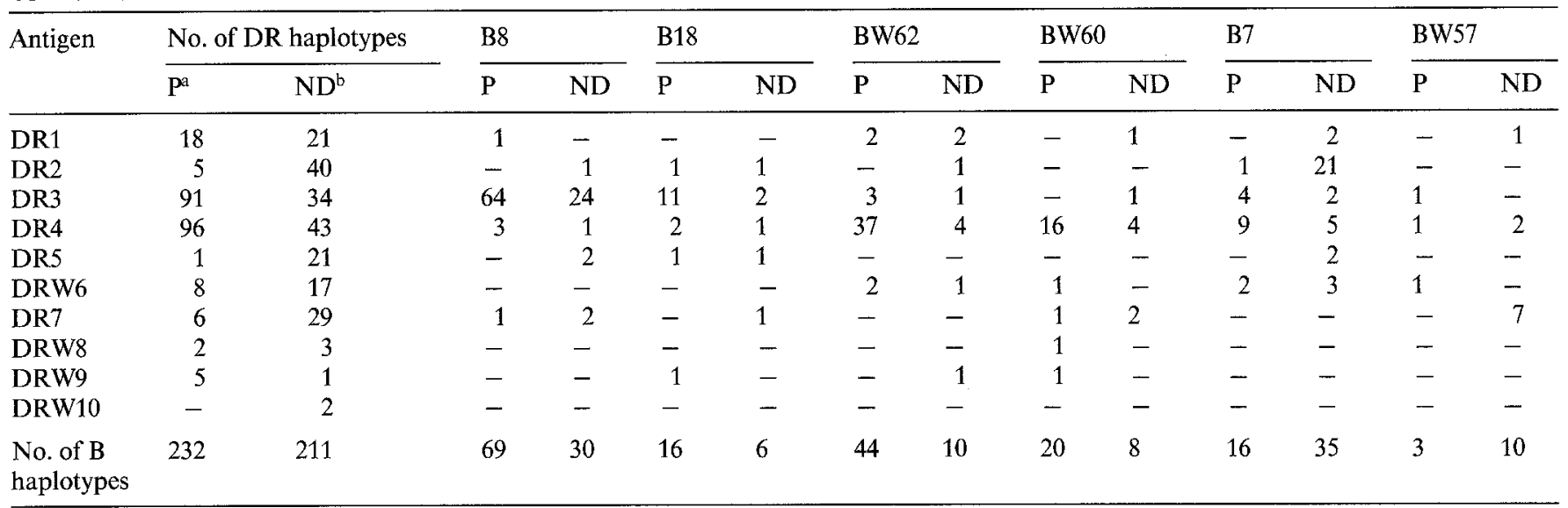

${ }^{a}$ Based on 116 probands because four recombinant probands, two probands in whom only phenotypes could be established and the one expaternal proband were excluded. ${ }^{b}$ 'Non-diabetic' parental haplotypes are defined as those unequivocally established haplotypes which never appear in either a diabetic parent or any diabetic child. All haplotypes involved in recombinations were excluded. As there are no adequate data available from healthy families, we used this approach to show the different degree of linkage disequilibrium between B and DR antigens in diabetic and 'non-diabetic' haplotypes

the question of whether or not there are immune response mechanisms determined by a gene or genes in linkage disequilibrium with both DR2 and DR7 which afford protection against $B$ cell damage by certain pancreatotropic viruses. This is a complex problem because when certain antigens are shown to have an increased frequency in patients with a particular disease, it follows that other antigens coded by genes at the same locus will show some resultant decrease in frequency. The virtual absence of DR2 in Type 1 diabetic probands, the reduced linkage of $\mathrm{DR} 2$ and $\mathrm{B} 7$ in diabetic haplotypes and the anecdotal B-DR recombinant involving DR2 suggest that this may not be a secondary phenomenon.

Previously we reported that in 150 HLA-A, B, C genotyped families there was a significant increased frequency of the A1, B8 haplotype compared with the alternative haplotype [24]. In the present study, we considered only those families with a single informative A1-CW7-B8-DR3 haplotype. Sixty percent of children inherited this particular haplotype compared with the expected $50 \%(p<0.05)$.

At the Eighth Histocompatibility Workshop [8], some evidence was put forward to suggest that there may be an association of DR4 with a younger age of onset of Type 1 diabetes and also with the season of onset. We have not been able to confirm this in the present study.

In conclusion, the very high frequency of DR3 and DR4 in Type 1 diabetic subjects and the hypothesis that these antigens themselves might be involved in the initial damage to the pancreatic B cells raises important speculative ideas for possible future therapy of this disease, particularly during the long prediabetic period before metabolic decompensation occurs [25]. It now seems clear from this and other studies $[16,17]$ that HLA-DR genotyping allows the identification of sib- lings who are at risk of developing diabetes. This provides valuable cohorts for long term follow-up with particular reference to DR dependent cellular immune events which may be operating in the initial pathogenesis.

Acknowledgements. This work has been supported by the Medical Research Council (E.W. and K.M.S), the British Diabetic Association, the Juvenile Diabetes Foundation and the Joint Research Board of St Bartholomew's Hospital. Valuable technical assistance was provided by B. Watson, V. Drummond, V. Algar and M. van Dam. We would also like to acknowledge all the tissue typing laboratories who kindly helped with HLA antisera and also Professor J.C. Woodrow for his valuable comments.

\section{References}

1. Singal DP, Blajchman MA (1973) Histocompatibility (HL-A) antigens, lymphocytotoxic antibodies and tissue antibodies in patients with diabetes mellitus. Diabetes 22: 429-432

2. Nerup J, Platz P, Anderson OO, Christy M, Lyngsoe J, Poulsen JE, Ryder LP, Staub-Nielsen L, Thomsen M, Svejgaard A (1974) HL-A antigens and diabetes mellitus. Lancet 2: 864-866

3. Cudworth AG, Woodrow JC (1975) HL-A system and diabetes mellitus. Diabetes 24: 345-349

4. Cudworth AG, Woodrow JC (1975) Evidence for HL-A linked genes in 'juvenile' diabetes mellitus. Br Med J 3: 133-135

5. Barbosa J, King R, Noreen H, Yunis EJ (1977) The histocompatibility system in juvenile, insulin-dependent diabetic multiplex kindreds. J Clin Invest 60: 989-998

6. Svejgaard A, Platz P, Ryder LP, Staub-Nielsen L, Thomsen M (1975) HL-A and disease associations: a survey. Transplant Rev 22: 3-43

7. Batchelor JR, Morris PJ (1977) Joint report on HLA and disease: juvenile onset diabetes. In: Bodmer WF, Batchelor JR, Bodmer JC, Festenstein H, Morris PJ (eds) Histocompatibility testing. Munksgaard, Copenhagen, pp 211-213

8. Svejgaard A, Platz P, Ryder LP (1980) Joint report: insulindependent diabetes mellitus. In: Terasaki PI (ed) Histocompatibility testing. 1980. UCLA, Tissue Typing Laboratory, California, pp 638-656 
9. Spielman RS, Baker L, Zmijewski CM (1980) Gene dosage and susceptibility to insulin-dependent diabetes. Ann Hum Genet 44: 135-150

10. Thomson G (1980) A two locus model for juvenile diabetes. Ann Hum Genet 43: 383-398

11. Bodmer WF (1980) The HLA system and disease. J R Coll Physicians 14: 43-50

12. Rubinstein P, Suciu-Foca N, Nicholson JF (1977) Genetics of juvenile diabetes mellitus. A recessive gene closely linked to HLA and with 50\% penetrance. $\mathrm{N}$ Engl J Med 297: 1036-1040

13. Tosi R, Tanigaki N (1980) Joint report: MT1. In: Terasaki PI (ed) Histocompatibility testing 1980. UCLA, Tissue Typing Laboratory, California, pp 556-563

14. Juji T, Maeda H, Omori K (1980) Joint report: MT2. In: Terasaki PI (ed) Histocompatibility testing 1980 . UCLA, Tissue Typing Laboratory, California, pp 564-566

15. Tosi R (1980) Joint report: MT3. In: Terasaki PI (ed) Histocompatibility testing 1980. UCLA, Tissue Typing Laboratory, California, pp 567-569

16. Christy M, Green A, Christau B, Kromann H, Nerup J, Platz P Thomsen M, Ryder LP, Svejgaard A (1979) Studies of the HLA system and insulin-dependent diabetes mellitus. Diabetes Care 2: 209-214

17. Deschamps I, Lestradet H, Bonaiti C, Schmid M, Busson M, Benajam A, Marcelli-Barge A, Hors J (1980) HLA genotype studies in juvenile insulin-dependent diabetes. Diabetologia 19: 189-193

18. Tosi R, Tanigaki N, Gentis D, Ferrara GB, Pressman D (1978) Immunological dissection of human Ia molecules. J Exp Med 148: 1592-1611

19. Festenstein H, Adams E, Burke J, Oliver RTD, Sachs JA, Wolf E (1973) The distribution of HL-A antigens in expatriates from East Bengal living in London. In: Dausset $\mathbf{J}$, Colombani $\mathbf{J}$ (eds) Histo- compatibility testing 1972. Munksgaard, Copenhagen, pp 175-178

20. Van Rood JJ, van Leeuwen A, Ploem JS (1976) Simultaneous detection of two cell population by two-colour fluorescence and application to the recognition of B cell determinants. Nature 262: 795-797

21. Haldane JBS (1955) The estimation and significance of the logarithm of a ratio of frequencies. Ann Hum Genet 20:309-311

22. Bengtsson BO, Thomson G (1981) Measuring the strength of associations between HLA antigens and diseases. Tissue Antigens 18: 356-363

23. Van Leeuwen A, Festenstein $H, D^{\prime}$ Amaro J, Navarette $C h$, Awad J, van Rood JJ (1980) A new B cell locus defined by a recombinant family. In: Terasaki PI (ed) Histocompatibility testing 1980. UCLA, Tissue Typing Laboratory, California, p 853

24. Cudworth AG, Wolf E, Gorsuch AN, Festenstein H (1979) A new look at HLA genetics with particular reference to Type 1 diabetes mellitus. Lancet 2:389-391

25. Gorsuch AN, Spencer KM, Lister J, McNally JM, Dean BM, Bottazzo GF, Cudworth AG (1981) Evidence for a long prediabetic period in Type 1 (insulin-dependent) diabetes mellitus. Lancet 2: 1363-1365

Received: 12August

and in revised form: 12 November 1982

Dr. Eva Wolf

Department of Diabetes and Immunogenetics

St. Bartholomew's Hospital Medical College

West Smithfield

London ECIA 7BE, UK 